\title{
Strengthening capacity for local evidence to inform local responses to HIV in a remote Solomon Islands health service
}

\author{
David MacLaren, ${ }^{a}$ Michelle Redman-MacLaren, ${ }^{a}$ Relmah Timothy-Harrington, ${ }^{\mathrm{b}}$ Rowena Asugeni, ${ }^{\mathrm{b}}$ Elmah Muse, \\ Emmy Jimuru, Kenny Moutoab and Rick Speare ${ }^{\text {cd }}$ \\ Correspondence to David MacLaren (e-mail: david.maclaren@jcu.edu.au)
}

Background: Documenting specific knowledge and attitudes about HIV in the culturally diverse nation of Solomon Islands is essential to inform locally targeted public health responses. As part of a large capacity-strengthening project at Atoifi Adventist Hospital in East Kwaio, Solomon Islands, researchers, using a 'learn-by-doing' process, worked with participants in public health research methods.

Methods: Overall, 43 people attended research capacity building workshops in 2011; eight joined the HIV study group. A cross-sectional survey including semi-structured interviews on HIV was conducted by the group. In February 2014, a hospital administrator was interviewed about how the 2011 study informed local HIV responses.

Results: Of the 53 survey participants, $64 \%$ self-assessed as having little or no HIV knowledge, but $90 \%$ knew HIV could be transmitted between men and women during sex. Less than $50 \%$ knew HIV could be transmitted between two men having sex, $45 \%$ thought HIV could be transmitted by mosquitoes and $55 \%$ agreed condoms help protect from HIV. Most participants reported negative attitudes towards people with HIV. Three years later the health administrator reported ad hoc responses to HIV because of low HIV prevalence, increasing noncommunicable diseases, staff turnover and resource shortages.

Discussion: This HIV study was used to strengthen research skills in local health professionals and community members in Solomon Islands. It showed that community members require accurate information about HIV transmission and that entrenched stigma is an issue. Although results provided local evidence for local response, ongoing health system challenges and little local HIV transmission meant HIV services remain rudimentary.

$\mathrm{R}$ educing the burden of HIV remains a global challenge. Despite the declining number of new infections of HIV globally, there was still an estimated 1.9 million people newly infected in 2013. ${ }^{1}$ In Oceania, up to 51000 people are living with HIV with almost 2100 new infections in 2012. ${ }^{2}$ Papua New Guinea has the greatest burden of HIV in Oceania with an estimated 21459 people living with HIV. $^{3}$ Solomon Islands has dramatically fewer cases with only 22 reported cases since 1994 with 14 people living with $\mathrm{HIV}^{4}$ Solomon Islands has a population of 610800 people speaking 63 languages. ${ }^{5,6}$ The majority (over $80 \%$ ) live in rural villages, and around $40 \%$ are under 14 years of age. ${ }^{7}$ The country shares a border with Papua New Guinea and they share many social, cultural, economic, political and health system characteristics. People regularly travel between the countries. This all puts the people of Solomon Islands at risk of HIV. ${ }^{7}$

Since 2009, there has been a concerted effort to have operational research embedded into the way local health services and community leaders engage with public health issues in East Kwaio on the remote eastern coast of the island of Malaita. This has included theoretical training and practical workshops in public health research methods using decolonizing methodologies and participatory research frameworks. ${ }^{8-10}$ Much of the training has been at Atoifi Adventist Hospital (AAH), a 65-bed general hospital with an attached Atoifi College of Nursing (now Pacific Adventist University - Atoifi

College of Medicine and Dentistry, James Cook University, McGregor Road, Smithfield, Cairns, Australia

Atoifi Adventist Hospital, East Kwaio, Malaita, Solomon Islands.

College of Public Health, Medical and Veterinary Sciences, James Cook University, James Cook Drive, Douglas, Townsville, Australia.

Tropical Health Solutions, 72 Kokoda Street, Idalia, Townsville Australia.

Submitted: 29 January 2015; Published: 6 May 2015

doi: 10.5365/wpsar.2015.6.1.015 
Campus). AAH is the largest nongovernmental hospital in the country, and the College (now University) educates almost half of the country's nurses. There are no roads, so village people access AAH by canoe or walking. Communication is by high frequency radio, landline, mobile telephone and periodic Internet. Electricity is provided by hydroelectric and diesel generators. Research capacity-strengthening for staff, students and community leaders has focused around local issues of parasitic disease, tuberculosis (TB) and HIV. ${ }^{11-14}$

Documenting specific knowledge and attitudes about a health issue such as HIV across the many divergent cultural groups in Solomon Islands is essential to inform locally targeted public health responses. ${ }^{15-19}$ Although Solomon Islands has low HIV prevalence $(<0.01 \%)$, there is a concerted effort to prevent HIV from expanding as it has in neighbouring Papua New Guinea (HIV prevalence 0.5\%). ${ }^{3}$ Voluntary confidential counselling and testing (VCCT) is established in many locations, but as in other countries in the region, VCCT is challenged by limited human and physical resources and a concern about lack of confidentiality. ${ }^{20}$

This study was the HIV component within a larger capacity-strengthening project with health professionals and community leaders. ${ }^{8-10}$ The overall aim was to strengthen research capacity at $\mathrm{AAH}$ and in surrounding communities using a 'learn-by-doing' process. The specific aims of the HIV study were to: (1) document people's knowledge of HIV transmission; and (2) examine attitudes and practices relevant to HIV transmission.

\section{METHODS}

In April 2011, 43 village leaders, other community members, health professionals and researchers from AAH and Australia participated in the capacity-strengthening workshop at $\mathrm{AAH} .{ }^{9} \mathrm{~A}$ subsection of eight people from the main group formed a team to investigate HIV. All described HIV as a public health concern. Despite the low prevalence in the country, all team members were concerned that the large HIV epidemic in neighbouring Papua New Guinea heightened the risk of HIV for Solomon Islanders. Many people from the villages of East Kwaio travel throughout Solomon Islands and perceive a risk of local villagers acquiring HIV when travelling. The team designed and implemented a study using two methods to document HIV knowledge, attitudes and practices in East Kwaio. Ethical approval was obtained from James Cook University Human Research Ethics Committee ( $\mathrm{H} 4002)$ and the $\mathrm{AAH}$ Research Ethics Committee (AAHREC3).

A cross-sectional survey was collaboratively designed based on knowledge, attitude and practice questions used in Papua New Guinea. ${ }^{21,22}$ Each question allowed for yes, no or unsure response. Open-ended questions included: "What do people in the community think about someone who has HIV?" and "Would people be willing to have confidential counselling and testing?" Questions about male circumcision for HIV prevention were asked of men. Semi-structured interviews were also conducted with key informants about male circumcision. Australian researchers co-facilitated training in survey design and data collection.

A convenience sampling method was used, with AAH patients or their family members on the hospital campus. An information sheet and consent form was provided to explain the study. If participants had limited or no literacy, the researcher explained the contents of the information sheet and consent form. Participants then signed or placed a thumbprint on the consent form. Researchers orally translated questions from English into Solomon Islands Pijin or Kwaio languages as required. Participant responses were written on forms in English or Pijin. Interviews were transcribed from digital voice recorders.

Data analysis was conducted by the research team at AAH. Quantitative data were entered into MS Excel and analysed using descriptive statistics. Data from openended questions were typed into MS Word. These data were analysed for codes and inductive in-vivo themes using a manual technique of printing transcripts, cutting transcripts into sentences or paragraphs and collating into themes. Consensus was reached within the research group before a sentence or paragraph was assigned to a theme or a new theme was created.

At the completion of the April 2011 workshop, results were presented to hospital and village leaders with the intent that they inform local HIV prevention responses. In February 2014, the Director of Nursing at AAH (who is responsible for both hospital and community outreach programmes) and an Australian researcher 
Figure 1. Proportion of correct responses to questions about HIV transmission through sexual and reproductive activities, Solomon Islands, 2011

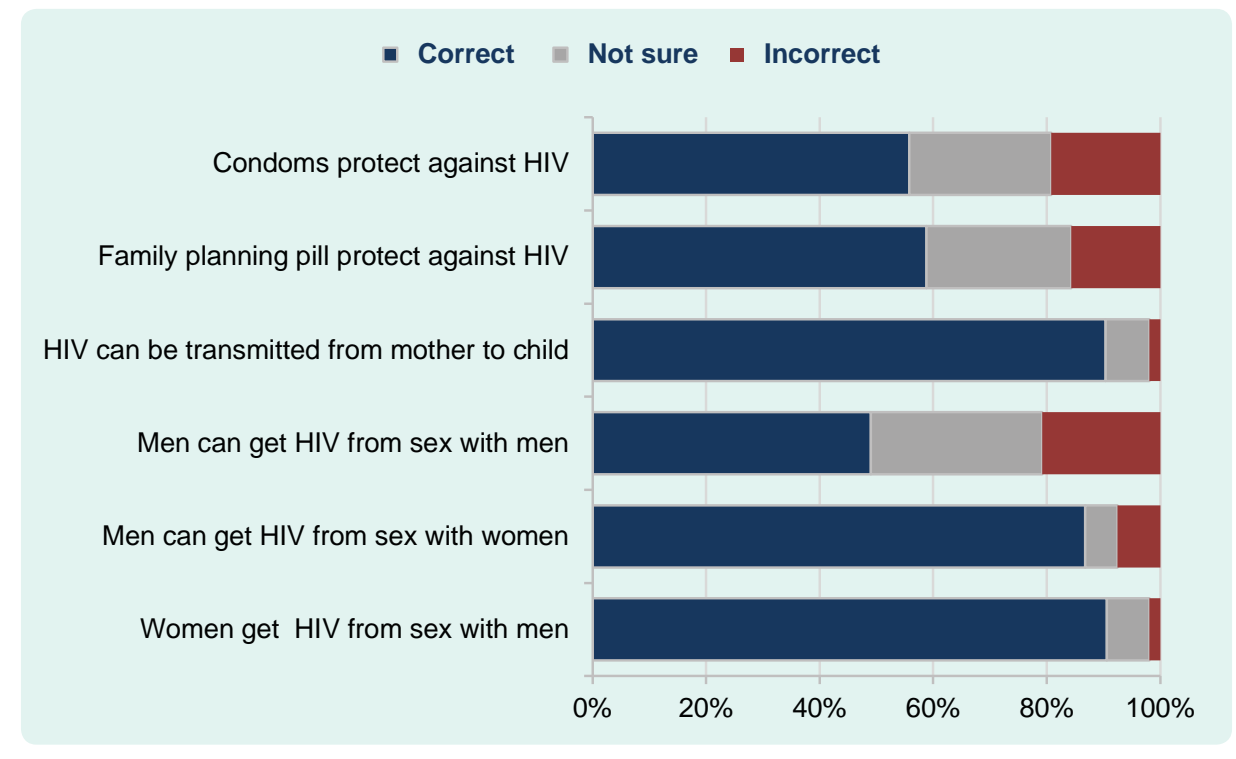

discussed two questions to document changes that had occurred at AAH because of the research findings. Questions were:

(1) How would you describe the HIV-related health services being provided at AAH in 2011 and 2014 ?

(2) What changes have been made to HIV-related health services at $A A H$ in response to results from the HIV study?

Responses were analysed for inductive themes.

\section{RESULTS}

\section{Cross-sectional survey}

In total, 53 people (27 female [51\%]) from 33 villages completed questionnaires. The median age of participants was 26 years (range 18-70 years). The majority of participants (52\%) were between 18 and 29 years with $58 \%$ currently married. Participants' religions included South Sea Evangelical Church (53\%), Catholic (21\%), Seventh-Day Adventist (17\%), Jehovah's Witness (7\%) and Ancestral religion (2\%).

Quantitative data were generated in two major areas: (1) sexual and reproductive health and HIV knowledge, and (2) knowledge of HIV transmission (Figures 1 and 2).
The majority of participants (89\%) knew HIV could be transmitted through heterosexual sex, but only half (49\%) knew HIV could be transmitted by men having sex with men. Around 45\% thought HIV could be transmitted by mosquitoes and just over $20 \%$ by a cough or sneeze. Just over half (56\%) thought condoms could protect from HIV, and $16 \%$ thought the family planning (oral contraceptive) pill could protect from HIV.

For the open-ended question, "What do people in the community think about someone who has HIV?", three major in-vivo themes were: (1) "send him/her somewhere else"; (2) "not close-might spread to others"; (3) "people may get cross [angry] or hate that infected man [person]". These in-vivo themes all expressed explicit stigma towards people living with HIV.

The first theme "send him/her somewhere else" related to physical and/or geographic proximity as demonstrated in the following response: "People in my community would not want people who have HIV in the village therefore they are planning to cut [with a machete] someone who has HIV in the village because if he lives he might spread it to the members of the community."

The second theme "not close-might spread to others" was about the potential of a HIV-positive person to infect others. "The people really don't want to stay or live with any person who has this sickness (HIV). 
Figure 2. Proportion of correct responses to questions about other routes of HIV transmission, Solomon Islands, 2011

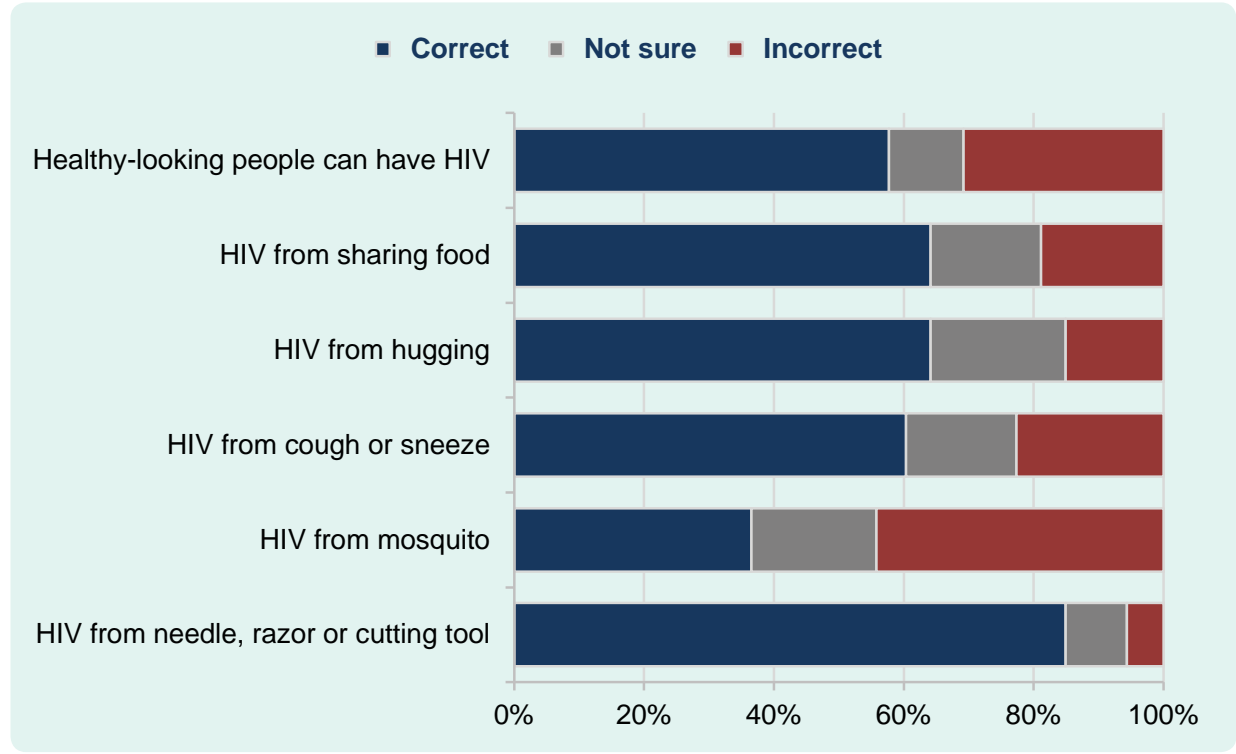

People have the feeling of disliking any infected person to share with them in any means." There were also perceptions presented that HIV-positive people would deliberately attempt to infect others. "Some people will have this idea to pass the disease to others that is why the people will not accept the infected person."

The third theme "people may be cross [angry] or hate that infected man [person]" was a collection of responses about feelings towards people living with HIV. The feelings expressed by participants included anger, fear, hatred and public humiliation (including mocking and gossip). One participant reported, "People in the community can talk spoil [verbally put down] the person and also even parents of the infected person." The strongest responses suggested a person should be killed for being HIV-positive: "They should be killed so they won't spread more HIVIAIDS" and "Olketa stap for dae blong olketa nao. Bae iumi kilim olketa nomoa" (they are going to die so let us just kill them). This was the theme with the most responses.

Despite these responses, the majority of participants reported that they would be willing to have an HIV test at $\mathrm{AAH}$. Of the 53 participants, $64 \%$ said they would be willing to have an HIV test, $26 \%$ were not willing and $6 \%$ were unsure. Participants explained their answers across three major topics: (1) willingness to test for HIV; (2) personal feelings about HIV status and test results; and (3) need for information about HIV.
Reasons given by participants were both individual concerns "Yes because I want my blood to be checked so that I know I am free from HIV" and consideration about their relationships/social relations: "I am not sure whether my husband is still faithful to me. So I would really like to know my status."

Concern was expressed about how others might treat the person if their HIV status became known: "Reason is that - they might make fun of me; people would hate me; not talk with me; my name would spread everywhere." There was also concern expressed about confidentiality with some stating that testing might be more acceptable if provided away from the local area: "If the service was available in Honiara (capital city) then would go because it is far from my community, no one will see me or take note of me."

Several participants requested more information about HIV: "I want to get right information so I can keep myself from the disease," and "If I might have HIV I will come and get more information."

\section{Male circumcision for HIV prevention}

The final question (for males only) asked about practices of male circumcision. One of the 26 male respondents had his foreskin cut and stated hygiene and Biblical reasons: "To avoid smell and also since during times of Moses (Jesus) God told them to circumcise 
that is why I must circumcise too. Therefore I cut my foreskin."

Many others also invoked a religious theme, but with a contrasting rationale that since God created us, we should not do anything to our body. Custom and/ or cultural beliefs were seen as important in deciding about male circumcision. One male cited the collective decision of men from his tribe not to cut their foreskins: "I was a heathen guy so not sure what reason I had to cut my foreskin. Such kind of things are bound to all our tribe not to cut our foreskin. If anyone did he will die, therefore all males of our tribe will not cut their foreskin." Other reasons given for not cutting their foreskin included health, shame and no one to do the procedure. Some said they had no reason and/or no interest in circumcision, "No interest in it because I do not like to spoil my body."

\section{Health service response to 2011 study findings}

Between April 2011, when the HIV study was conducted and reported, and February 2014 numerous challenges and opportunities emerged in response to HIV at AAH.

The Director of Nursing explained that in 2011, a certified VCCT counsellor provided HIV services from the AAH Outpatients Department. The VCCT counsellor was a female Registered Nurse and provided services to antenatal mothers during routine antenatal screening; testing was conducted using Rapid Test Kits in the AAH laboratory. Patients with positive results were referred to Honiara for confirmation and further testing. Occasionally, members of the general public (mostly women) directly requested VCCT services. The service was not promoted publically and very few village people knew about the service. At the end of 2011, the VCCT counsellor left AAH with no female VCCT counsellor since then. In 2011, the male TB nurse was trained and certified to provide VCCT services. HIV testing is now routinely offered to patients that test positive for TB. There has been no routine HIV screening of antenatal mothers since the end of 2011, and no community-based HIV services operate from AAH.

Information about HIV is included in community health education programmes delivered by the Primary Health Care Outreach team. However, with low HIV prevalence, a need to maintain immunization coverage and escalating diabetes and hypertension, HIV is not prioritized. In addition, there are no specific sexually transmitted infections (STI) services at AAH. This means when village people suspect an STI they seek out hospital nurses they trust will not disclose their STI status to ask for diagnosis and treatment. In this context, there is almost no contact tracing or partner treatment. A lack of STI/HIV services, limited knowledge of STI/ HIV policies, staff shortages and competing demands of other diseases all mean there is an ad hoc approach to $\mathrm{STI} / \mathrm{HIV}$ in East Kwaio.

Following this reflection on the lack of progress since the HIV research study, the Director of Nursing said that steps to prioritize HIV services must be revitalized. "Everitin slip bek nomoa, hem mus wek up moa" (everything went back to sleep, it must wake up). AAH management plans to identify an STI nurse to lead the local STI response, including HIV, beyond the current ad hoc response. "We don't want to wait until there is a crisis."

\section{DISCUSSION}

This study showed that people living in remote East Malaita have a fragmented understanding of HIV transmission. Levels of knowledge about heterosexual transmission and transmission from mother to child were high, but they were low for transmission between men who have sex with men. Levels of knowledge about the ability of condoms to prevent HIV were also low. Levels of knowledge about other routes of perceived transmission were inadequate, particularly transmission by mosquitoes, coughing and hugging. Most participants reported negative attitudes towards people living with HIV. These results are arguably due to the low HIV prevalence and limited HIV education in the area. Most participants would have had little or no experience of, or interaction with, people living with HIV. The findings from this study in East Malaita are consistent with other survey data reported from Solomon Islands showing moderate knowledge and negative attitudes towards people living with $\mathrm{HIV}^{7,23}$

The overall aim of the study was to strengthen research capacity at AAH in partnership with Australian researchers and local communities to systematically conduct locally relevant health research to inform local responses. ${ }^{24-30}$ This HIV study has demonstrated that, 
similar to neighbouring Papua New Guinea, ${ }^{19,31}$ locally responsive studies can be conducted with input from key hospital and community partners and that data can be collected on the sensitive sexual health topic of HIV, including practices of male circumcision.

This study has highlighted many of the challenges of delivering HIV and STI services in remote parts of Solomon Islands. Low HIV prevalence, staff turnover, maintaining technical capacity, social and cultural expectations of patients seeking specific staff and the competing demands of both communicable and noncommunicable diseases all resulted in relatively few of the study results directly informing STI/HIV services. ${ }^{16,32,33}$ This is in contrast to the outcome of the TB component of the overall study which informed dramatic and fundamental changes to TB services at $A A H,{ }^{12,13,25}$ most likely due to TB having a much higher prevalence. Given the seriousness of the stigma and exclusion against people with HIV highlighted in this study, there is substantial risk for people wishing to have an HIV test at AAH. HIV and STI services need to ensure confidentiality and that stigma is constantly challenged.

Results from small studies can provide evidence to directly inform specific health messages to be delivered locally. The parallel TB study at AAH documented that culturally appropriate health information delivered in the local Kwaio language can reduce the proportion of people who think TB is caused by sorcery. ${ }^{13}$ Given many people in East Kwaio have limited literacy and there are very few health information resources, the hospital outreach team regularly delivers oral presentations in open village meetings. It is therefore essential that the hospital outreach team deliver specific presentations to dispel perceived risk of HIV from mosquitoes, coughing and hugging, provide accurate information about men having sex with men and the protective effects of condoms.

When this study commenced in 2011, there were projections of rapidly expanding HIV epidemics in both Solomon Islands and neighbouring Papua New Guinea and a desire for locally informed response at AAH. However, the epidemic did not occur and the health service has since focused on other issues. Had the HIV epidemic projections been realized, HIV testing and treatment services would have needed to be given a greater priority. However, as reported in 2014, the STI response (including HIV) in East Malaita needs improvement, and the results of this study can inform HIV education and testing within antenatal clinics, TB services and a re-designed STI service.

There are several limitations in this study, including the modest number of participants, convenience sampling method and that some of the researchers were learning research skills as they conducted the study. The fact that the structured questionnaires were written in English and orally translated into Pijin or Kwaio by the interviewer may have influenced the results, including the nuances of responses to open-ended questions. However, strengths of the study included that hospital and village leaders identified the topic as a priority and data were successfully collected using a gendered approach relevant to the local context. Data were collectively analysed and highlighted issues of importance to both local and outside members of the study team. This is the first report of HIV knowledge and of people's intentions to access HIV services at AAH in East Malaita.

\section{CONCLUSION}

This study in remote East Kwaio, Solomon Islands, showed there was accurate knowledge about heterosexual and mother-to-child HIV transmission but poor knowledge about transmission between men who have sex with men and the role of condoms. These gaps need to be addressed, including the important role of condoms in HIV prevention. Health services have the opportunity to integrate HIV into existing or new health programmes to maximize staff and resources and public health need. Ongoing operational research is required to document the changing nature of HIV services and knowledge required for local health responses in an area with limited resources. This study demonstrates that a modest project undertaken within an ongoing research capacity-strengthening programme can provide locally relevant information to inform local responses to HIV despite the challenges of working and conducting research in remote Pacific island locations.

\section{Conflicts of interest}

None declared. 


\section{Funding}

Funding for research capacity-strengthening at $\mathrm{AAH}$, which included this study, was provided by James Cook University through the Research Infrastructure Block Grant Scheme.

\section{Acknowledgements}

Thank you to East Kwaio community members Rex Fo'olego, Wallace Arifanaboo and Silas Laubeu who contributed to the study design, data collection, analysis and reporting of this study. Thank you very much to the East Kwaio community members who generously volunteered to participate in the study. A Research Infrastructure Block Grant funded by James Cook University and in-kind contributions from AAH and Atoifi College of Nursing enabled the research.

\section{References:}

1. Global summary of the AIDS epidemic 2013. Geneva, World Health Organization, 2014 (http://www.who.int/hiv/data/epi core_dec2014.png?ua=1, accessed 2 April 2015).

2. Global Report: UNAIDS report on the global AIDS epidemic 2013. Geneva, Joint United Nations Programme on HIV/AIDS, 2013.

3. Papua New Guinea 2013 HIV\&AIDS estimations \& projections. Port Moresby, National Department of Health, National AIDS Council Secretariat, and UNAIDS, 2013.

4. Solomon Islands global AIDS response progress report 2014 Honiara, Ministry of Health and Medical Services, 2014.

5. 2013 Pocket Statistical Report. Noumea, Secretariat of the Pacific Community, 2014.

6. Tryon D, Hackman B. The languages of the Solomon Islands: an internal classification. Canberra, Pacific Linguistics, 1983.

7. Bad sickness rubbish sicki: understanding HIV and AIDS risk and vulnerability among Solomon Islands youth. Suva, UNICEF Pacific, 2011.

8. Redman-Maclaren ML et al. "We can move forward": challenging historical inequity in public health research in Solomon Islands. International Journal for Equity in Health, 2010, 9:25. doi:10.1186/1475-9276-9-25 pmid:21050492

9. Redman-MacLaren $M$ et al. Mutual research capacity strengthening: a qualitative study of two-way partnerships in public health research. International Journal for Equity in Health, 2012, 11:79. doi:10.1186/1475-9276-11-79 pmid:23249439

10. Redman-Maclaren ML et al. Research workshop to research work: initial steps in establishing health research systems on Malaita, Solomon Islands. Health Research Policy and Systems, 2010, 8:33. doi:10.1186/1478-4505-8-33 pmid:21034512

11. Massey PD et al. TB questions, East Kwaio answers: community-based participatory research in a remote area of Solomon Islands. Rural and Remote Health, 2012, 12:2139. pmid:23094978

12. Massey PD et al. Progress towards TB control in East Kwaio, Solomon Islands. Rural and Remote Health, 2013, 13:2555. pmid:23731167
13. Massey PD et al. Steps on a journey to TB control in Solomon Islands: a cross-sectional, mixed methods pre-post evaluation of a local language DVD. BMC International Health and Human Rights, 2015, 15:1. doi:10.1186/s12914-015-0041-3 pmid:25644087

14. Harrington HA et al. A practical strategy for responding to a case of lymphatic filariasis post-elimination in Pacific Islands. Parasites and Vectors, 2013, 6:213. doi:10.1186/1756-3305-6-218 pmid:23880226

15. MacLaren D, Kekeubata E. Reorienting health services through community health promotion in Kwaio, Solomon Islands. Promotion \& Education, 2007, 14:78-79. doi:10.1177/10253 823070140021701 pmid:17665704

16. MacLaren D etal. Incorporating sociocultural beliefs in mental health services in Kwaio, Solomon Islands. Australasian Psychiatry, 2009, 17 Suppl 1;S125-127. doi:10.1080/10398560902948381 pmid: 19579125

17. Furusawa T. The roles of western biomedicine and folk medicine in rural Solomon Islands: a quantitative analysis of villagers' response to illness. Tropical Medicine and Health, 2006, 34:83-91. doi:10.2149/tmh.34.83

18. Kelly A et al. The art of living: the social experience of treatments for people living with HIV in Papua New Guinea. Goroka, Papua New Guinea Institute of Medical Research, 2009.

19. Vallely $A$ et al. Male circumcision for HIV prevention in PNG: A summary of research evidence and recommendations for public health. Papua New Guinea Medical Journal, 2011, 54:91-108. pmid:24494506

20. Butt L. Can you keep a secret? Pretences of confidentiality in HIV/ AIDS counseling and treatment in Eastern Indonesia. Medical Anthropology, 2011, 30:319-338. doi:10.1080/01459740.20 11.560585 pmid:21590584

21. MacLaren $D$ et al. Foreskin cutting beliefs and practices and the acceptability of male circumcision for HIV prevention in Papua New Guinea. BMC Public Health, 2013, 13:818. doi:10.1186/1471-2458-13-818 pmid:24015786

22. Buchanan $\mathrm{H}$ et al. Behavioural surveillance research in rural development enclaves in Papua New Guinea: a study with the Oil Search Limited workforce - Presentation. Port Moresby, National Research Institute, 2010.

23. National Statistics Office. Solomon Islands Demographic and Health Survey. Noumea, Secretariat of the Pacific Community, 2009.

24. Kekeubata E et al. Community-based research for improved TB services. East Kwaio, Atoifi Adventist Hospital, Atoifi Health Research Symposium, 2015 (http://www.atoifiresearch.org.sb/ node/92, accessed 27 April 2015).

25. Asugeni $\mathrm{R}$ et al. Community and health service responses to culturally safe tuberculosis ward at Atoifi Adventist Hospital, Solomon Islands. East Kwaio, Atoifi Adventist Hospital, Atoifi Health Research Symposium, 2015 (http://www.atoifiresearch. org.sb/node/92, accessed 27 April 2015).

26. Oloifana-Polosovai $\mathrm{H}$ et al. A marked decline in the incidence of malaria in a remote region of Malaita, Solomon Islands, 2008 to 2013. Western Pacific Surveillance and Response Journal, 2014, 5:30-39. doi:10.5365/wpsar.2014.5.3.002 pmid:25320674

27. Harrington $\mathrm{H}$ et al. Is Iymphatic filariasis still in Shortland Islands? Noumea, Atoifi Adventist Hospital, Atoifi Health Research Symposium, 2015 (http://www.atoifiresearch.org.sb/node/92, accessed 27 April 2015).

28. Harrington $\mathrm{H}$. Elimination of soil transmitted helminths: one village at a time. East Kwaio, Atoifi Adventist Hospital, Atoifi 
Health Research Symposium, 2015 (http://www.atoifiresearch. org.sb/node/92, accessed 27 April 2015).

29. Jimuru $C$ et al. Infection control at Atoifi Adventist Hospital: responding to the measles epidemic. East Kwaio, Atoifi Adventist Hospital, Atoifi Health Research Symposium, 2015 (http://www. atoifiresearch.org.sb/node/92, accessed 27 April 2015).

30. Fa'anuabae C. Investigating an outbreak of bloody diarrhoea Sinalagu, Kwaio Region. East Kwaio, Atoifi Adventist Hospital, Atoifi Health Research Symposium, 2015 (http://www. atoifiresearch.org.sb/node/92, accessed 27 April 2015).
31. Tommbe R et al. Researching male circumcision for HIV prevention in Papua New Guinea: a process that incorporates science, faith and culture. Health Research Policy and Systems/BioMed Central, 2013, 11(1):1-8.

32. Harrington $H$, Asugeni $R$, MacLaren D. Comment: Inter-Island referrals in Solomon Islands: a remote hospital perspective. Rural and Remote Health, 2013, 13:2415. pmid:23600912

33. Harrington H, Taolo L, MacLaren D. Triathlon in the Tropics South Pacific Style. In: Edwards A, Leicht A, editors. Science of sport, exercise and physical activity in the tropics. New York, Nova Science Publishers, Inc, 2014, pp 83-90. 